\title{
Student Reflections on the IDS40 Conference
}

\author{
Nicholas Benequista and Ian Macauslan
}

\author{
1 Introduction \\ The IDS fortieth anniversary conference brought \\ together representatives from IDS peer \\ organisations, partners and funders, to discuss the \\ reinvention of development research. As two IDS \\ students who also attended the conference, we \\ present our reflections on the discussions from our \\ distinct perspective, influenced by our broad \\ overview of IDS research, our multidisciplinary \\ training and, above all, our immediate proximity to \\ teaching and training at IDS.
}

We were surprised by the way the conference seemed to underplay the role of teaching and training as a form of both learning and dissemination. Indeed, what makes the absence more surprising is that the IDS teaching and training programme has been under intense discussion recently as the Institute restructures its degree programmes for 2007 - the most recent of many efforts IDS has made over the last four decades to reinvent itself as a centre of education.

Many of the salient challenges to development research that were raised at the conference also resonate with issues arising during our studies at IDS. We were particularly struck by the juxtaposition of a claimed need to break down the geographic disciplinary and subject biases and the enduring parochialism in development research; the problematic relationship with the private sector; and the problems that derive from patterns of development research funding, including an elite student body, insufficient attention to theorising and the privileging of certain methodologies and subjects.

In this article, we will first explain who we are, as individuals and as IDS students, before elaborating on our reactions to some of the ideas we were presented with during the conference.

\section{Our positionality}

We (the two authors) share some common characteristics. To begin with, we are American and English, both male, white and raised as Christians. Although we cannot claim to be representative of the majority of students at IDS, these characteristics do not distinguish us from our classmates as much as one might suspect.

Over the last three decades, about 44 per cent of the MPhil students have been from countries in Europe or North America. Another 16 per cent have come from East Asia, and 13 per cent have come from Latin America. Students from South Asia and sub-Saharan Africa have each constituted less than 10 per cent of the intake.

Nonetheless, it is important to point out why two students of our particular profile are writing this article. The most immediate reason is due to the casual coincidence that we helped to document the conference. We were invited to assist with this, in part because we were in Brighton while others were away. We have also been active at IDS beyond our coursework, bringing us into contact with the staff who organised the event. Our native English and our personal histories helped to make us more comfortable than some of our peers in approaching the research Fellows to involve ourselves in their work. It is also worth mentioning that we offered to write this article, partly because we felt we had something to say, but perhaps more importantly, because we felt entitled to say it.

Apparent differences aside, whether from Ankara, Arizona, Oxford or Osaka, we have personally felt comfortable among all our peers, who are generally from the ranks of the upper classes and privileged ethnic groups of their respective countries. Philosophically and politically, we have also found 
much in common with our classmates. Some of our classmates could have completed their next degree at Harvard or Oxford, but chose IDS for its reputation for challenging orthodoxy and questioning the establishment. But that can also be a weakness. $A$ lack of serious defenders of trade liberalisation as a strategy for development, for example, can mean less meaningful discussion in the classroom.

Like many of our classmates, we also chose this programme for its broad disciplinary coverage and its balance between theory and practice. We consider ourselves generalists by nature, and after a year or two at IDS, we are multidisciplinary by training. We now know as much about power theory as we do about economic growth models, and we shrink from the idea of identifying ourselves with a particular discipline. Our broad perspective also gives us a unique perspective on IDS research. (And we might even venture that IDS students may understand the complete dimensions of the Institute's work even better than some its Fellows.)

One last common characteristic is that we are relatively young, which of course carries many implications. We are perhaps still somewhat malleable, to the point of caprice at times, but also less jaded and cynical. Furthermore, our personal lives have not yet been subsumed by our professional lives. As such, we have friends in banking, business management, psychology and computer science, among other fields, which often challenge the wisdom we have accepted from IDS Fellows and encourage us to think in ways totally foreign to development paradigms. It is safe, we believe, to say we treat new ideas more fairly due to our relative youth.

We would like to comment in this article on a few of the ideas that emerged from the speeches and discussions at the conference; some of which were new to us, and others which seemed anachronistic. We do this in the hope that our reflections will perhaps provide an insight into how IDS is cultivating the likely participants of its next anniversary conference, be that in 20 or 40 years from now.

\section{A 'big push' for development research}

A number of the speakers and participants at the conference called for a broadening or expansion of development research. We were able to identify three distinct dimensions, in particular where participants suggested development research could be more holistic
First, speakers including IDS Director, Lawrence Haddad, and the Ford Foundation's Michael Edwards, asked whether development has bankrupted itself by diligently maintaining a theoretical division between the 'North' and the 'South'; terms that may have come into use more recently, but reflect no more and perhaps even less - sophistication than their predecessors such as First World and Third World, developed or developing nations.

Conceptually, development research - with support and inspiration from other fields - is beginning to sketch broader alternative paradigms which have their foundations in work on global value chains and transnational citizen action, to name just two examples. But it is not a lack of theory that prevents students and researchers from writing about social exclusion in both Bangladesh and France. Rather, it is the political economy of development that is unnecessarily converted into dogmatic custom and convention in the classroom.

Yet, the dismantling of the North-South divide in development research is going to require more than a paradigm shift and audacious teaching since it is reinforced by the unevenness of globalisation. As Arjun Appadurai (2000) points out, globalisation unequally distributes the resources for learning, teaching and cultural criticism that are most vital for the forms of collaboration necessary for understanding globalisation. The IDS teaching programme would have to consider very radical changes indeed to respond to this even greater obstacle to surpassing the North-South paradigm.

As a second area of expansion, a number of other participants mentioned the need for including more disciplines in development research; namely inviting historians and psychologists to join the economists, political scientists, anthropologists and sociologists now dominating the field. We agree that such a broadening would provide potentially eye-opening insights.

More historical analysis, for example, could help us to interrogate our framing of development as a primarily post-colonial project with a beginning, middle and end and thus challenge us, as Michael Edwards suggested, to think instead about the continual processes of social transformation that development is fundamentally trying to engender. Perhaps more importantly, historical analysis may also 
lead us to recognise the ways in which development covertly suppresses social change.

Though in favour of integrating new disciplines in general, we are perplexed at the ostensible enthusiasm for a multidisciplinary approach in development which seems to be juxtaposed with the disciplinary parochialism so evident in the field. That schizophrenic attitude affects us even as students at IDS, where despite the personal insights we gain from crossing disciplines, we feel compelled to confine our term papers and dissertations to a single discipline (that of the Fellow we surmise to be marking it), lest we be penalised for failing the standards of rigour.

Lastly, the conference was peppered with suggestions for new, or sometimes forgotten, topics in development research. 'I think our rooms are populated by many elephants and our discomfort is showing', said Haddad in his closing speech. Sex, capitalism and religion, among other topics, were said to remain beyond the current ken of development research.

Again, our reaction is to applaud such an initiative, but with a slight reservation. The problem we foresee is that development research may currently lack the theoretical tools for this endeavour. Some scholars suggest returning to Marxist critiques to highlight the effects of global capitalism on power and poverty. As two students taught to distrust grand narratives, we would suggest this will only yield change in conjunction with radical new methodologies that depart from the pristine, disembedded Marxist analysis of the past. And rushing headlong and ill-equipped into topics of religion and sex, for example, has recently produced clumsy and counterproductive results. As such, we are inclined to think that perhaps new topics cannot be incorporated without new disciplines, which points to the need for something like a 'big push' in development research, orchestrating wholesale changes simultaneously on multiple fronts.

\section{The private sector}

Many researchers at the conference were unhappy with the nature of funding for development research and practice. One problem noted by some participants is that private sector funding is often tied to a particular framing of the question and researchers may not be permitted to publish findings that are unpalatable to their funders. $A$ second issue relates to the policy focus of much funding. It is perceived that there are limited resources available for theoretical work, and that this has restricted the theoretical sophistication and comprehensiveness of development studies. This is clearly not desirable, especially at a time when it is becoming increasingly apparent that the dominant structures of economy and society in high-income countries may be the drivers of global climate chaos and impoverishment. We take up this latter issue more specifically below. But first, we raise the question of why there appears to be so little engagement by development researchers with the private sector.

In the final session of the conference, David Croft, Director of Ethical Sourcing and Sustainability at Cadbury-Schweppes, argued that development research needs to address all actors that play a part in development, including the private sector. His perception (shared by others) was that this does not happen enough, and he argued that this is due partly to innate conservatism and risk-avoidance in the private sector, but also a lack of effectiveness from development researchers.

There are three good reasons for engaging with individuals in the private sector. First, many of the world's ills are attributed to rapacious corporations or irresponsible banks. Teaching on our MPhil courses that deal with this (options on Agriculture and Rural Development; Rules of Engagement in the Global Economy) has, in our experience, argued that the problem is not that individuals in the private sector are immoral. The problem is that the system in which they work creates incentives to do things that have negative consequences for the poor and the environment. Take two examples: Supermarket management reports to shareholders who demand high share price, which is largely dependent on profits. Supermarkets therefore employ buyers whose bonuses depend on sourcing produce at the lowest price possible. Since supermarkets now occupy such dominant positions in the buyers' market, sellers are forced to accept supply relationships that are both quite unprofitable and uncertain (as supermarkets with global reach can switch their supplier at short notice as global costs change) (see Barrientos and Dolan 2006). These 'immiserising relationships' have negative consequences for vulnerable workers and smallholders. A second example could be traders in financial markets who have bonuses that are linked to short-term profits. Profits in financial markets are often linked to variables that have positive 
relationships with the behaviour of traders: if you go one way and all the other traders go the other, you will lose. Traders therefore have incentives to herd together over the short term, and when this means rapidly pulling money in and out of low-income countries, it can cause currency collapse or problems in investment, with obvious serious negative consequences for the poor in these countries (as we have seen in Korea or some of the former Soviet republics).

We prefer to demonise the system because many of our friends work in the private sector and we resist portraying them as immoral or uncaring. In fact, many of our friends, when newly out of university, wanted to work in the development sector but could not, for various financial reasons (in itself an indictment of the accessibility of the development sector, on which more below). Many private sector professionals donate significant parts of their salaries to charities, do pro bono legal work, and all kinds of weird and wonderful things to raise money for various causes. Yet, individuals within companies regularly make decisions that activists vilify on the basis of being immoral and uncaring. If otherwise caring individuals make decisions that have terrible consequences, is it because they are unaware of or deliberately ignoring those consequences, or because there is a system that essentially forces them to do so? If it is the former, development research could certainly engage with them much more actively to inform; if the latter, development workers could strive harder to form alliances with caring individuals.

The second (related) reason for engaging with the private sector is that it has tremendous potential to achieve positive change both in 'internal' company practice (such as equitable trading relationships, environmental sustainability, or responsible lending) and through 'external' corporate social responsibility projects. There are vast sums of money at stake. Postmaterialist consumers are increasingly basing their choice of investments and purchases on ethics, and companies have incentives to address this. Many of our friends in the private sector are willing to engage with these issues and are aware of the constraints they face. Development researchers can help to bridge the gap between critical activists and concerned but constrained private sector employees. Perhaps, for instance, supermarkets can be persuaded to engage in open-book costing (making public their costs and profit margins) as a profit-making activity, on the grounds that ethical consumers like to see where their money goes and will purchase the products of more transparent companies.

A third reason for engaging with the private sector is that it might improve research outcomes or practices. The private sector has massive and efficient research departments from which development researchers could learn. They are often ahead of the development sector on many issues. For instance, it was noted at the conference that insurance premiums had already been adjusted to take account of climate change, while research on social protection is only just starting to recognise the issue. It is critical, of course, that the development sector maintains and enhances its (currently often limited) independence from corporate interests. To this end, it should seek research funding from an engaged private sector, which might be less tied.

One way to help overcome the innate conservatism of the private sector might be to consider more closely the possible mutual benefits arising from closer engagement. And development training might incorporate specific modules on the benefits of and constraints on engagement, recognising explicitly the systemic problems, to which we now turn.

\section{Patterns of development funding}

In her presentation, Barbara Harriss-White made the connections between many of the concerns about development research that were raised at the conference and current systems of funding. Knowledge production has become a competitive industry and this, she argued, has led to the commodification of policy formulation. Research is driven by this, and is increasingly focused on policy rather than theory. Moreover, she argued, since the private sector is now involved in funding both the state (especially through private partnerships for service delivery) and research, in many instances development research fails to engage critically on issues surrounding capital and economic development. These arguments are useful in explaining the relatively little attention paid by development researchers to, for example, the relationship between the global economy and climate change, or more broadly, between systemic incentives and negative consequences.

As suggested above, we believe that engaging with individuals in the private sector may mitigate the co-optation of research. Engagement must not come at the expense of critical voice. On the other 
hand, to borrow another of Harriss-White's analogies, we suggest that preaching the sins of the capitalist system to the academy choir will have limited impact. Development researchers need to find accessible and engaging ways to raise these issues with those outside the academy, and inside the structures of capital, who are in a position to influence change in the private sector.

One of the most obvious points of connection is through teaching and training, especially since students are a captive audience (at an impressionable age as we have already noted) and continue into careers as development practitioners or policymakers. However, as we noted earlier, it is important to ask a question about who these students are and where they come from.

At IDS, the students are invariably quite well-off relative to their compatriots (although clearly, some students are from much wealthier backgrounds than others). And IDS students are usually either from the 'North' of the 'global North', or the 'North' of the 'global South'. This is influenced by both the high fees, the relatively low earnings in many

development jobs (compared with equivalent work in the private sector), and the requirement of many development agencies for postgraduate degrees. Since development is concerned with addressing injustice (whether globally or locally), it is surely imperative to have at least a few students from the receiving end. There are serious questions around why development is such an elite occupation, and whether it promotes and protects itself as such. Why require a postgraduate degree for job applicants? Why are there so few scholarships available for extremely expensive courses? Why are students from low-income countries travelling to the global North to study development? It is difficult not to conceive of development as a post-colonial project when its teaching and job market is structured in this way.

The next 40 years will contain many challenges for development and development research. It seems some radical changes may be required and here we have tried to outline some approaches we find promising (noting that they reflect our positionality as IDS students from the North). It is our hope that IDS can prepare its students to meet those challenges and that this article will serve as a modest contribution to that end.

\section{References}

Appadurai, A. (2000) 'Grassroots Globalization and the Research Imagination', Public Culture 12.1: 1-19

Barrientos, S. and Dolan, C. (eds) (2006) Ethical Sourcing in the Global Food System, London: Earthscan 